\title{
Mutation analysis of the ATR gene in breast and ovarian cancer families
}

\author{
Katri Heikkinen, Virpi Mansikka, Sanna-Maria Karppinen, Katrin Rapakko and Robert Winqvist
}

Department of Clinical Genetics, Oulu University Hospital/University of Oulu, Oulu, Finland

Corresponding author: Robert Winqvist, robert.winqvist@oulu.fi

Received: 24 Feb 2005 Revisions requested: 18 Mar 2005 Revisions received: 8 Apr 2005 Accepted: 11 Apr 2005 Published: 6 May 2005

Breast Cancer Research 2005, 7:R495-R501 (DOI 10.1186/bcr1037)

This article is online at: http://breast-cancer-research.com/content/7/4/R495

(c) 2005 Heikkinen et al.; licensee BioMed Central Ltd.

This is an Open Access article distributed under the terms of the Creative Commons Attribution License (http://creativecommons.org/licenses/by/ 2.0), which permits unrestricted use, distribution, and reproduction in any medium, provided the original work is properly cited.

\begin{abstract}
Introduction Mutations in BRCA1, BRCA2, ATM, TP53, CHK2 and PTEN account for only $20-30 \%$ of the familial aggregation of breast cancer, which suggests the involvement of additional susceptibility genes. The ATR (ataxia-telangiectasia- and Rad3related) kinase is essential for the maintenance of genomic integrity. It functions both in parallel and cooperatively with ATM, but whereas ATM is primarily activated by DNA double-strand breaks induced by ionizing radiation, ATR has been shown to respond to a much broader range of DNA damage. Upon activation, ATR phosphorylates several important tumor suppressors, including p53, BRCA1 and CHK1. Based on its central function in the DNA damage response, ATR is a plausible candidate gene for susceptibility to cancer.
\end{abstract}

Methods We screened the entire coding region of the ATR gene for mutations in affected index cases from 126 Finnish families with breast and/or ovarian cancer, 75 of which were classified as high-risk and 51 as moderate-risk families, by using conformation sensitive gel electrophoresis and direct sequencing.

Results A large number of novel sequence variants were identified, four of which - Glu254Gly, Ser1142Gly, IVS24$48 G>A$ and IVS26+15C $>$ T - were absent from the tested control individuals $(n=300)$. However, the segregation of these mutations with the cancer phenotype could not be confirmed, partly because of the lack of suitable DNA samples.

Conclusion The present study does not support a major role for ATR mutations in hereditary susceptibility to breast and ovarian cancer.

\section{Introduction}

Of all breast and ovarian cancers, 5-10\% are due to genetic predisposition [1]. Mutations in the two high penetrance genes BRCA1 and BRCA2 are well known, but they account for only $20-30 \%$ of the familial aggregation of breast cancer. The remaining cases could be the result of a few additional, yet unidentified, high penetrance mutations, but the polygenic model may provide a more plausible explanation [2]. According to this model, genetic susceptibility to breast cancer is due to several loci, each conferring a modest independent risk [3]. Because the protein products of the genes thus far associated with breast and/or ovarian cancer predisposition are central players in the pathways involved in cell cycle checkpoint functions, and in the sensing, transduction and repair of DNA lesions [4], other similarly acting genes may represent new potential candidates.
The ATR (ataxia-telangiectasia- and Rad3-related) kinase is essential for the maintenance of genomic integrity. It is a key activator of the cellular responses to DNA lesions [5]. In response to DNA double-strand breaks induced by ionizing radiation ATR, along with ATR-interacting protein, acts in parallel with ATM (ataxia-telangiectasia mutated), which is defective in the neurodegenerative disorder ataxia-telangiectasia and is also associated with breast cancer susceptibility [6-9]. Whereas ATM is responsible for the immediate and rapid response to double-strand breaks, ATR joins in later and maintains the phosphorylated state of specific substrates. However, this is not the main role played by ATR; it also responds to ultraviolet-induced lesions, stalled replication forks and hypoxia [5]. In response to these events, ATR phosphorylates key proteins in various branches of the DNA damage response pathways, such as p53, BRCA1, CHK1 and Rad17, thereby 
activating DNA repair, cell cycle checkpoints, or apoptosis $[10,11]$.

The cellular functions of ATR are indispensable, as demonstrated in mice, in which biallelic disruption of ATR leads to early embryonic lethality. In contrast, $A T R^{+/-}$mice exhibit only a small decrease in survival but tumor incidence is increased [12]. In humans a connection between ATR defects and tumorigenesis has also been suggested, mainly by studies reporting somatic changes in ATR in gastric and endometrial cancers exhibiting microsatellite instability $[13,14]$. Consequently, it has been proposed that ATR serves as a haploinsufficient tumour suppressor on a mismatch repair deficient background [15].

Recently, inherited defects in ATR signalling were shown to associate with Seckel syndrome, because patients in two families were found to be homozygous for a hypomorphic ATR mutation. Seckel syndrome is a heterogenous recessive disorder that is characterized by dwarfism, developmental delay and severe microcephaly. It shares an overlap in clinical features with two recessive cancer susceptibility syndromes, Nijmegen breakage syndrome and Fanconi anemia (FA) $[16,17]$. Interestingly, the gene that is defective in two FA complementation groups, namely FA-B and FA-D1, has been identified as $B R C A 2$ - a major breast cancer susceptibility gene $[18,19]$. In addition, carriers of the Nijmegen breakage syndrome Slavic founder mutation appear to be at increased risk for breast cancer [20]. Thus far, predisposition to cancer has not been reported in patients with Seckel syndrome. However, various cell lines in which ATR has been inactivated exhibit genetic instability, and this may predict proneness to cancer [17].

Based on this, we wanted to determine whether ATR germline mutations are involved in susceptibility to breast and/or ovarian cancer, and conducted a mutation analysis of all 47 coding exons and exon-intron boundaries in the affected index cases in 126 families.

\section{Materials and methods Subjects}

The index cases of 126 breast and/or ovarian cancer families originating from northern Finland were screened for ATR germline mutations. Of the studied families, 94 were affected by breast, 29 by breast/ovarian and three by ovarian cancer. All index cases had been diagnosed with either breast or ovarian cancer. 75 of the families were classified as high-risk families and were defined as follows: three or more cases of breast and/or ovarian cancer in first- or second-degree relatives; or two cases of breast and/or ovarian cancer in first- or second-degree relatives, of which at least one had early disease onset (age $\leq 35$ years), bilateral disease, or multiple primary tumours. Most of the high-risk families contained three or more cancer cases. The remaining 51 families contained two cases of breast and/or ovarian cancer in first- or seconddegree relatives and were considered to be at moderate disease risk. All of the high-risk families had previously been screened for germline mutations in BRCA1, BRCA2, CHK2 and TP53 [21-23] and 10 families were known to have disease-related mutations in BRCA1 or BRCA2. The frequencies of all observed germline variants were assessed in either 100 or 300 control individuals, who were anonymous cancer-free blood donors originating from the same geographical region as the studied families.

All patients gave informed consent for acquisition of pedigree data and blood specimens for use in a study on cancer susceptibility gene mutations. Approval to perform the study was obtained from the Ethical Board of the Northern Ostrobothnia Health Care District and the Finnish Ministry of Social Affairs and Health.

\section{Mutation analysis}

DNA was extracted from blood lymphocytes using either the standard phenol-chloroform protocol or the Puregene D-50K purification kit (Gentra, Minneapolis, MN, USA). Screening of the protein encoding and exon-intron boundary regions of ATR was done by conformation sensitive gel electrophoresis (CSGE), which is a cost-efficient way to scan for mutations with high detection sensitivity and specificity $[24,25]$, or by direct sequencing. Sequencing analysis was performed using the Li-Cor IR2 4200-S DNA Analysis system (Li-Cor Inc., Lin-

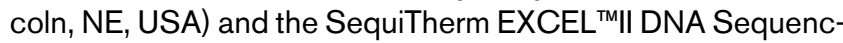
ing Kit-LC (Epicentre Technologies, Madison, WI, USA). Oligonucleotides for CSGE and sequencing (Table 1) were designed using Primer3 software [26], utilizing sequence information obtained from public databases. Polymerase chain reaction conditions for CSGE and sequencing are available upon request.

\section{Statistical analyses}

Fisher's exact test or $\chi^{2}$ test was used to determine statistical significance (SPSS version 12.0 for Windows; SPSS Inc., Chicago, IL, USA). All $P$ values were two sided.

\section{Results}

Mutation analysis revealed several alterations in the ATR gene. Altogether, 23 nucleotide substitutions were observed: 17 in the exon and six in the intron regions (Tables 2 and 3 ). Eleven of the exonic changes resulted in amino acid substitutions, eight of which were novel and three were polymorphisms reported in the single nucleotide polymorphism database [27]. The location of the amino acid changes is summarized in Fig. 1. All observed nucleotide alterations were assessed for possible effects on splicing consensus sequences [28], and the coding sequence variants were tested using the ESEfinder program [29] to identify those that reduced the exonic splicing enhancer (ESE) score below the calculated threshold. 
Table 1

Primers used to amplify exons and splice junctions of ATR

\begin{tabular}{|c|c|c|}
\hline Exon & Forward $^{a}$ & Reverse \\
\hline 1 & ccgggtcctatgcagaaaag & aggggagagcacgtgaaac \\
\hline 2 & cattgacactgaacacatttgatg & tctaaaactacatggagaaaatgct \\
\hline 3 & ggcccacagtctggtttct & gtaatatttcagaagagcagtaaaagg \\
\hline $4 a$ & tcgtcaaggatttagcaaatga & acgagtaagaaccattaataaagtgac \\
\hline $4 b$ & atgtgatgggtcatgctgtg & gctcttcatagagtttcaattggtc \\
\hline $4 c$ & tccaaaaattaaatccctagcaa & tctcacatagaccttcctgacttg \\
\hline $4 d$ & aaactctgtgtcatgtttgaagac & gccagactacactatgaaaatcatta \\
\hline 5 & cattcttgctgcctatgaataa & aaatcaaagcacttaactaaagctga \\
\hline 6 & tctaaatatgtttcatgttttaaccaa & tgagtcaagtgaataatgagtaaaca \\
\hline 7 & tggctttactacaattttatgtttgac & cacttaggcttcaggcaaaa \\
\hline $8^{b}$ & tttaaaagagatatgattaaggaaaag & cacacattcttgtgagcactt \\
\hline 9 & aaatgtattttaagtgttacttgactttt & aaccctgcatacatagccaga \\
\hline 10 & gtcccaaattaagcaagactattt & caaggcttcagtctaattcttttac \\
\hline 11 & tcatggcatattatttgttgac & gaacaataaaattaactggttaaagaa \\
\hline 12 & gaggttgataatttttgtttttaacat & ccatttttaacagcaagcaaa \\
\hline 13 & tgagtcaacatgaatttatttgtagat & aaagaaaagcaagcaaaataaaac \\
\hline 14 & ctctatggtggcttaaaaagtattagt & caaagtcaaaatctagaatggaatg \\
\hline 15 & ctccaaatatgtgtggcattt & accctctttcctagaagaatgttac \\
\hline 16 & ctcctgatgtactaatagcatgttaaa & tgaccaaaaatatgatttcttcaat \\
\hline 17 & gcttttggagaaacttaattaacca & tgtttgtagctagatgcagaattt \\
\hline $18^{b}$ & tgtccttagggctcatctgc & tgaacccaatttccctcaaa \\
\hline 19 & gctgccttttaatctattgtttg & cattaccatcagtaattttgagacat \\
\hline 20 & ggccttagtttcaacttttactttaca & caggaattagctatcagaataggact \\
\hline 21 & gagaattcaggcctttggaa & aatgtcattttgtcatcttttcttt \\
\hline 22 & aactcatcaaaaactagctgaaaaa & ggataagctgaatagttctttgtaaat \\
\hline 23 & ccatggaaaaagcagtacacc & aaaacaaaaaggagtttcacaagt \\
\hline 24 & gcataaataaagcgaagtgcaa & ggccaaaaaaatcgcatta \\
\hline 25 & agtcaactgaaggagttgctg & ttgtgtgtgctaggcattcag \\
\hline 26 & ttatctcacatgctactctttgaca & catttcctactaataggtagcctttc \\
\hline 27 & ttagaatggttagctttagatgtcata & agaactgataaagggaagagctaa \\
\hline 28 & caattgttctgttgttagttacattct & gcatagcatataaaacattcaataaaa \\
\hline 29 & aaacaggtggttttatagttttatttc & aaggtttccagagttcctattca \\
\hline 30 & aagggcaataaggtaaatagtaat & aaattacccaattcactaactaaaaa \\
\hline 31 & gaacaaaatacaatataatgcaaattcaa & accgcacccatcctaaaact \\
\hline 32 & ttgatatttcagctgaccattttatc & ccaaactcactatcaattatttactcaaa \\
\hline 33 & caactgtgtattttaaattctttatttctg & cacccccaaataatatccaa \\
\hline $34^{b}$ & attgggaacagaggctttca & gacatttccctggccattac \\
\hline 35 & caaaaacataatgaactaatacttttgc & catgtgctttgccatatagactt \\
\hline
\end{tabular}


Table 1 (Continued)

Primers used to amplify exons and splice junctions of $\boldsymbol{A T R}$

\begin{tabular}{lll}
\hline 36 & tcacatactttgatccctaatca & acctagaatatgctaagacatgtga \\
37 & ttttgtgaaaacggtatgtgg & agactgtccagccaaatctga \\
38 & tgtgaaatgaactgatatactgatttt & cgccctggaacttgtatcta \\
39 & aactctcatcatgaatacttttaagtt & aaaaactgctttattaagacaaatcat \\
40 & ttgtaaaagtgaaattttgttatagtgg & ttgtgaaatacacttttatcttaattga \\
41 & tttacacagaaattttggcccta & caactctgaaataaaagcaatctgg \\
42 & tttggttatgaaatgaacaatcttt & aggaagggatggaaacactt \\
43 & agtagatgtttcttgtccaattttaac & catatgaggccaatataaatctaaaa \\
44 & gttgttatggttgaatgtttatttta & caaggaagatacagttgttgagaa \\
45 & tggacatgaagttctttgagtaaa & caaacatatgtaggggccaat \\
46 & agcttctcatccttcacttaaa & aactatagctgcatatcaagttca \\
$47 \mathrm{a}$ & gggtattggtcagtaaaatggta & ccacagattcataccaaatgc \\
$47 \mathrm{~b}$ & gaaggacatgtgcattaccttatac & cttgcttgtttcttgcaaatatag \\
\hline
\end{tabular}

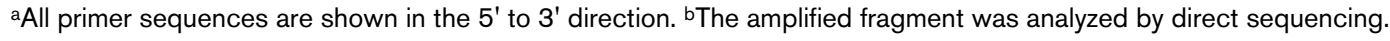

Of the observed amino acid substitutions, four were located in known functional sites: Arg2008Leu and Tyr2132Asp to the FAT (FRAP/ATM/TRRAP) domain, and Arg2425Gln and lle2435Val to the PI3Kc (phosphoinositide 3-kinase related catalytic) domain. The novel Arg2008Leu, Tyr2132Asp and lle2435Val alterations occurred in one index case each. Interestingly, Arg2008Leu appeared to have an effect on two ESEs (SF2/ASF and SC35), as predicted by the ESEfinder program.

Arg2008Leu was identified in a patient with both ovarian and colon cancer at age 51 years, and her sister, diagnosed with breast cancer at age 72 years, was found to be a carrier. However, because Arg2008Leu, Tyr2132Asp or Ile2435Val carriers were also observed in control individuals, these changes were all classified as rare variants. Arg2425Gln is a common polymorphism described in the single nucleotide polymorphism database, and its frequency was similar in cases $(27.8 \%)$ and controls (24.0\%).

The rest of the amino acid substitutions were all located outside the kinase and FAT/FATC domains, although two of these, Glu254Gly and Ser1142Gly, were absent from the tested controls. Glu254Gly affects a nonconserved residue, and was seen in one patient diagnosed with breast cancer at age 37 years. However, her maternal cousin, with bilateral breast cancer at ages 45 and 55 years, was not a carrier. The other change, Ser1142Gly, affects a residue that is also conserved in ATR of Xenopus laevis and in mei41 of Drosophila melanogaster [30]. Ser1142Gly was seen in two index cases with breast cancer $(2 / 126 ; P=0.09)$. In the first family the patient was diagnosed at age 64 years. Two of her daughters had breast cancer at ages 49 and 40 years, but both tested negative for Ser1142Gly. Also, two sisters of the index had breast cancer at unknown ages, but no samples were available for mutation testing. In the second family the index patient was diagnosed at age 59 years, but her sister, who had breast cancer at age 45 years, was not a carrier. Neither Glu254Gly nor Ser1142Gly had an affect on splicing consensus sequences or ESEs.

Of the six intronic changes, two were absent from the tested control individuals: IVS24-48G $>$ A was observed in the index case of three families $(3 / 126 ; P=0.03)$ and IVS26+15C>T was observed in one case. Unfortunately, only one additional DNA sample from an affected relative was available for mutation testing, and this maternal cousin of the index case proved negative for IVS24-48G $>$ A. Also IVS31-74G $>$ A was found more frequently in cases $(8.7 \%)$ than in control individuals $(4.3 \%)$, but the difference was only marginally significant (odds ratio 2.1, 95\% confidence interval 0.92-4.85; $P=$ $0.07)$. None of the observed intron changes had an affect on consensus splice sites.

\section{Discussion}

ATR plays a critical role in the maintenance of genomic integrity. A number of tumour suppressor proteins act downstream of ATR, placing it high in the DNA damage response cascade [5]. Impaired ATR signalling has been shown to result in Seckel syndrome, but thus far predisposition to cancer in these patients has not been reported [16]. Nevertheless, cell lines with inactivated ATR exhibit genetic instability, which may suggest proneness to cancer [17].

To investigate the possible role played by ATR germline mutations in hereditary predisposition to breast and ovarian cancer, 
Table 2

\begin{tabular}{|c|c|c|c|c|c|c|}
\hline \multirow[t]{2}{*}{ Exon } & \multirow[t]{2}{*}{ Nucleotide change } & \multirow[t]{2}{*}{ Effect on protein } & \multicolumn{2}{|c|}{ Carrier frequency } & \multirow[t]{2}{*}{$P$} & \multirow[t]{2}{*}{ Status $^{a}$} \\
\hline & & & Familial cases & Controls & & \\
\hline 3 & $268 C>T$ & His90Tyr & $12.7 \%(16 / 126)$ & $10.3 \%(31 / 300)$ & 0.50 & Novel \\
\hline \multirow[t]{3}{*}{4} & $632 \mathrm{~T}>\mathrm{C}$ & Met211Thr & $54.0 \%(68 / 126)$ & $47.3 \%(142 / 300)$ & 0.20 & Reported \\
\hline & $761 A>G$ & Glu254Gly & $0.8 \%(1 / 126)$ & - $(0 / 300)$ & 0.30 & Novel \\
\hline & $891 \mathrm{G}>\mathrm{C}$ & Lys297Asn & $1.6 \%(2 / 126)$ & $2.3 \%(7 / 300)$ & 1.00 & Reported \\
\hline \multirow[t]{2}{*}{8} & $1776 \mathrm{~T}>\mathrm{A}$ & Gly592Gly & $50.8 \%(64 / 126)$ & $41.0 \%(41 / 100)$ & 0.18 & Reported \\
\hline & $1815 \mathrm{~T}>\mathrm{C}$ & Asp605Asp & $46.8 \%(59 / 126)$ & $49.0 \%(49 / 100)$ & 0.79 & Reported \\
\hline 14 & $2946 C>T$ & Phe982Phe & $0.8 \%(1 / 126)$ & $2.0 \%(6 / 300)$ & 0.68 & Novel \\
\hline 17 & $3424 A>G$ & Ser1142Gly & $1.6 \%(2 / 126)$ & - $(0 / 300)$ & 0.09 & Novel \\
\hline 21 & $3893 \mathrm{~A}>\mathrm{T}$ & Asp1297Val & $0.8 \%(1 / 126)$ & $1.0 \%(3 / 300)$ & 1.00 & Novel \\
\hline 26 & $4576 A>G$ & Ile1526Val & $4.0 \%(5 / 126)$ & $2.0 \%(6 / 300)$ & 0.31 & Novel \\
\hline 30 & $5208 T>C$ & Tyr1736Tyr & $23.8 \%(30 / 126)$ & $37.0 \%(37 / 100)$ & 0.03 & Reported \\
\hline 32 & $5459 \mathrm{~T}>\mathrm{C}$ & Tyr1820Tyr & $26.2 \%(33 / 126)$ & $31.0 \%(31 / 100)$ & 0.43 & Reported \\
\hline 35 & $6023 G>T$ & Arg2008Leu & $0.8 \%(1 / 126)$ & $0.3 \%(1 / 300)$ & 0.51 & Novel \\
\hline 38 & $6394 \mathrm{~T}>\mathrm{G}$ & Tyr2132Asp & $0.8 \%(1 / 126)$ & $0.3 \%(1 / 300)$ & 0.51 & Novel \\
\hline \multirow[t]{2}{*}{43} & $7274 G>A$ & Arg2425Gln & $27.8 \%(35 / 126)$ & $24.0 \%(72 / 300)$ & 0.46 & Reported \\
\hline & $7303 A>G$ & Ile2435Val & $0.8 \%(1 / 126)$ & $0.3 \%(1 / 300)$ & 0.51 & Novel \\
\hline 47 & $7875 A>G$ & Gln2625Gln & $27.0 \%(34 / 126)$ & $35.0 \%(35 / 100)$ & 0.19 & Reported \\
\hline
\end{tabular}

aNovel or reported in the National Center for Biotechnology Information single nucleotide polymorphism database http://www.ncbi.nlm.nih.gov/ SNPI.

Table 3

\section{Observed sequence variation in the intron regions of $A T R$}

\begin{tabular}{|c|c|c|c|c|c|}
\hline \multirow[t]{2}{*}{ Location } & \multirow[t]{2}{*}{ Nucleotide change } & \multicolumn{2}{|c|}{ Carrier frequency } & \multirow[t]{2}{*}{$P$} & \multirow[t]{2}{*}{ Status ${ }^{a}$} \\
\hline & & Familial cases & Controls & & \\
\hline IVS2-51 & $A>T$ & $9.5 \%(12 / 126)$ & $9.0 \%(9 / 100)$ & 0.89 & Novel \\
\hline IVS16-26 & $\mathrm{T}>\mathrm{A}$ & $2.4 \%(3 / 126)$ & $4.3 \%(13 / 300)$ & 0.41 & Novel \\
\hline IVS18-22 & $\mathrm{G}>\mathrm{C}$ & $4.8 \%(6 / 126)$ & $4.0 \%(12 / 300)$ & 0.72 & Novel \\
\hline IVS24-48 & $G>A$ & $2.4 \%(3 / 126)$ & $-(0 / 300)$ & 0.03 & Novel \\
\hline IVS26+15 & $\mathrm{C}>\mathrm{T}$ & $0.8 \%(1 / 126)$ & - $(0 / 300)$ & 0.30 & Novel \\
\hline IVS31-74 & $\mathrm{G}>\mathrm{A}$ & $8.7 \%(11 / 126)$ & $4.3 \%(13 / 300)$ & 0.07 & Novel \\
\hline
\end{tabular}

aNovel or reported in the National Center for Biotechnology Information single nucleotide polymorphism database http://www.ncbi.nlm.nih.gov/ SNPI.

the whole coding region of the gene was screened for mutations in the index cases from 126 families. We found a number of novel sequence variants, but we did not identify any clearly pathogenic alterations. Only two of the observed missense changes, Glu254Gly and Ser1142Gly, were absent from control individuals. However, because the variants did not segre- gate with the cancer phenotype in these families, they are unlikely to be important cancer susceptibility alleles. Evaluation of the intronic variants IVS24-48G $>A$ and IVS26+15C $>T$ is more difficult because only one additional DNA sample was available for mutation testing, but neither had any affect on consensus splicing sequences. The possible association of 


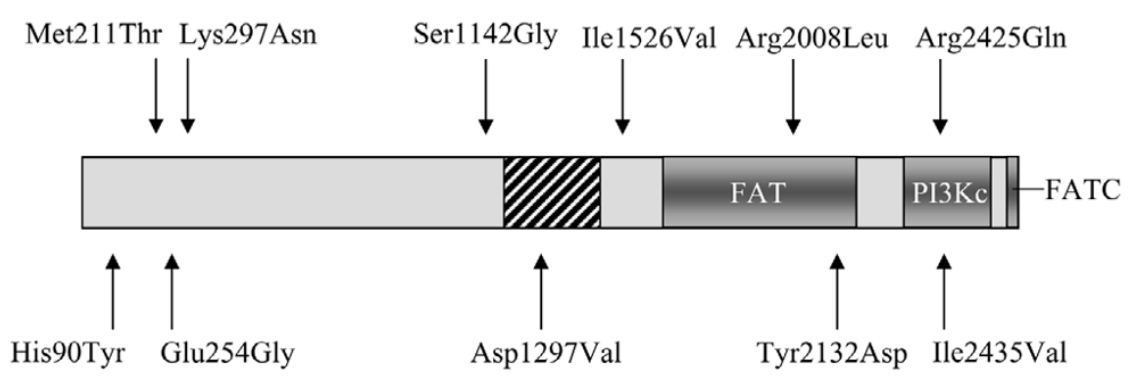

Wa functionally undefined region of homology between ATM and ATR

Structure of ATR and the location of observed amino acid changes.

the identified rare variants with predisposition to cancer must be demonstrated by more extensive case-control studies.

The performed mutation analysis is to our knowledge the first to investigate the possible association of germline ATR mutations with cancer predisposition. However, the results of the study suggest that ATR is not involved in hereditary susceptibility to breast and ovarian cancer. The lack of deleterious germline mutations could reflect a fundamental role for ATR in cell viability, including DNA replication [5]. Nonetheless, because ATR changes have thus far been reported only in gastric and endometrial tumours exhibiting microsatellite instability, it is also possible that breast and/or ovarian cancer is not the primary cancer phenotype associated with germline mutations in this gene $[13,14]$. These findings need confirmation by other studies.

\section{Conclusion}

Based on its central role in the maintenance of genomic integrity, we hypothesized that germline mutations in ATR may account for some breast and/or ovarian cancer families. However, analysis of 126 index cases suggests that ATR mutations do not play a major role in hereditary susceptibility to these cancers.

\section{Competing interests}

The author(s) declare that they have no competing interests.

\section{Authors' contributions}

$\mathrm{KH}$ and $\mathrm{VM}$ conducted the screening studies. $\mathrm{RW}, \mathrm{KH}$ and VM participated in the design of the study and performed the statistical analysis. S-MK and KR helped to draft the manuscript. All authors read and approved the final manuscript.

\section{Acknowledgements}

The authors thank Drs Guillermo Blanco, Ulla Puistola, Aki Mustonen and Jaakko Ignatius, and Nurse Outi Kajula for their help in patient contact; and the Academy of Finland, University of Oulu, Oulu University
Hospital, Nordic Cancer Union and Cancer Foundation of Northern Finland for providing the means for the current investigation. The kind participation of all patients has been of utmost importance to this study.

\section{References}

1. Claus EB, Risch N, Thompson WD: Genetic analysis of breast cancer in the cancer and steroid hormone study. Am J Hum Genet 1991, 48:232-242.

2. Houlston R, Peto J: The future of association studies of common cancers. Hum Genet 2003, 112:434-435.

3. Pharoah PDP, Antoniou A, Bobrow M, Zimmern RL, Easton DF, Ponder BAJ: Polygenic susceptibility to breast cancer and implications for prevention. Nat Genet 2002, 31:33-36.

4. Nathanson KL, Weber BL: 'Other' breast cancer susceptibility genes: searching for more holy grail. Hum Mol Genet 2001, 10:715-720.

5. Abraham RT: Cell cycle checkpoint signaling through the ATM and ATR kinases. Genes Dev 2001, 15:2177-2196.

6. Swift M, Reitnauer PJ, Morrell D, Chase CL: Breast and other cancers in families with ataxia telangiectasia. $N$ Engl J Med 1987, 316:1289-1294.

7. Teraoka SN, Malone KE, Doody DR, Suter NM, Ostrander EA, Daling JR, Concannon P: Increased frequency of ATM mutations in breast carcinoma patients with early onset disease and positive family history. Cancer 2001, 92:479-487.

8. Chenevix-Trench G, Spurdle AB, Gatei M, Kelly H, Marsh A, Chen $X$, Donn K, Cummings M, Nyholt D, Jenkins MA, et al.: Dominant negative ATM mutations in breast cancer families. J Nat/ Cancer Inst 2002, 94:205-215.

9. Thorstenson YR, Roxas A, Kroiss R, Jenkins MA, Yu KM, Bachrich T, Muhr D, Wayne TL, Chu G, Davis RW, et al.: Contributions of ATM mutations to familial breast and ovarian cancer. Cancer Res 2003, 63:3325-3333.

10. Shiloh Y: ATM and related protein kinases: safeguarding genome integrity. Nat Rev Cancer 2003, 3:155-168.

11. Zou L, Elledge SJ: Sensing DNA damage through ATRIP recognition of RPA-ssDNA complexes. Science 2003, 300:1542-1548.

12. Brown EJ, Baltimore D: ATR disruption leads to chromosomal fragmentation and early embryonic lethality. Genes Dev 2000, 14:397-402.

13. Menoyo A, Alazzouzi $H$, Espin $E$, Armengol $M$, Yamamoto $H$ Schwartz S Jr: Somatic mutations in the DNA damageresponse genes ATR and CHK1 in sporadic stomach tumors with microsatellite instability. Cancer Res 2001, 61:7727-7730.

14. Vassileva V, Millar A, Briollais L, Chapman W, Bapat B: Genes involved in DNA repair are mutational targets in endometrial cancers with microsatellite instability. Cancer Res 2002, 62:4095-4099. 
15. Fang $Y$, Tsao CC, Goodman BK, Furumai R, Tirado CA, Abraham RT, Wang XF: ATR functions as a gene dosage-dependent tumor suppressor on a mismatch repair-deficient background. EMBO J 2004, 23:3164-3174.

16. O'Driscoll M, Ruiz-Perez VL, Woods CG, Jeggo PA, Goodship JA: A splicing mutation affecting expression of ataxia-telangiectasia and Rad3-related protein (ATR) results in Seckel syndrome. Nat Genet 2003, 33:497-501.

17. O'Driscoll M, Jeggo PA: Clinical impact of ATR checkpoint signalling failure in humans. Cell Cycle 2003, 2:194-195.

18. Wooster R, Bignell G, Lancaster J, Swift S, Seal S, Mangion J, Collins N, Gregory S, Gumbs C, Micklem G: Identification of the breast cancer susceptibility gene BRCA2. Nature 1995, 378:789-792.

19. Howlett NG, Taniguchi T, Olson S, Cox B, Waisfisz Q, De DieSmulders C, Persky N, Grompe M, Joenje H, Pals G, et al:: Biallelic inactivation of BRCA2 in Fanconi anemia. Science 2002, 297:606-609.

20. Górski B, Debniak T, Masojc B, Mierzejewski M, Medrek K, Cybulski C, Jakubowska A, Kurzawski G, Chosia M, Scott R, et al:: Germline 657del5 mutation in the NBS1 gene in breast cancer patients. Int J Cancer 2003, 106:379-381.

21. Huusko $P$, Pääkkönen $K$, Launonen V, Pöyhönen $M$, Blanco $G$, Kauppila A, Puistola U, Kiviniemi H, Kujala M, Leisti J, et al.: Evidence of founder mutations in Finnish BRCA1 and BRCA2 families. Am J Hum Genet 1998, 62:1544-1548.

22. Allinen $M$, Huusko $P$, Mäntyniemi $S$, Launonen $V$, Winqvist $R$ : Mutation analysis of the CHK2 gene in families with hereditary breast cancer. Br J Cancer 2001, 85:209-212.

23. Rapakko K, Allinen M, Syrjäkoski $K$, Vahteristo $P$, Huusko $P$, Vähäkangas K, Eerola $\mathrm{H}$, Kainu T, Kallioniemi OP, Nevanlinna $\mathrm{H}$, et al: Germline TP53 alterations in Finnish breast cancer families are rare and occur at conserved mutation-prone sites. $\mathrm{Br} J$ Cancer 2001, 84:116-119.

24. Körkkö J, Annunen S, Pihlajamaa T, Prockop DJ, Ala-Kokko L: Conformation sensitive gel electrophoresis for simple and accurate detection of mutations: comparison with denaturing gradient gel electrophoresis and nucleotide sequencing. Proc Natl Acad Sci USA 1998, 95:1681-1685.

25. Ganguly A: An update on conformation sensitive gel electrophoresis. Hum Mutat 2002, 19:334-342.

26. Primer 3 Input [http://frodo.wi.mit.edu/cgi-bin/primer3/ primer3 www.cgi]

27. db SNP [http://www.ncbi.nlm.nih.gov/SNP/]

28. Berkeley Drosophila Genome Project [http://www.fruitfly.org/ seg tools/splice.html]

29. ESE finder [http://rulai.cshl.edu/tools/ESE/]

30. Perry J, Kleckner N: The ATRs, ATMs, and TORs are giant HEAT repeat proteins. Cell 2003, 112:151-155. 